not a disease of the spinal marrow or membranes, and it be not complicated. It does not appear that either of them tried it. Erichsen (vol. ii., p. 215) says he has " never known any but a fatal result follow the removal of these tumours by ligature, scissors, or knife." Gross (vol.ii., p.188) speaks equally discouragingly of the results, and $I$ cannot find a case on record which has been treated successfully by this method. Dr. Nevins mentioned, at the Liverpool Pathological Society, in 1850, three cases in which puncture had been tried. One case was cured, the gentleman being then forty years of age; the second died; and the third was quite well at the end of three or four months, with the sac contracted. Dr. Hana has related a case in which spontaneous rupture of the sac took place after measles, and the child recovered. Cases have been cured by puncture followed by injection of iodine, as proposed by Dr. Brainerd. The present case was doubtless one in which the spinal cord had no, or only slight, connexion with the sac. Ollivier states that when the disease is not complicated with hydrocephalus, he has generally found the spinal marrow traversing the sac unaltered; but if coexistent with hydrocephalus, or if the canal of the spinal marrow be distended with fluid, the cord may be flattened out, as it were, so as to apparently line the sac. The gradual compression by the tightening of the ligatures may have contributed a little to the favourable result in this casc, and should another opportunity present itself to me I shall not hesitate to adopt the same course. Mottram-in-Longdendale, Cheshire, Sept. 1869.

\section{IMPROVED PESSARY FOR FLEXIONS OF THE UTERUS.}

BY JOHN CLAY, Esq.

FROFESSOR OF MIDWIFERY, QUEEN'S COLIEGE, BIRUINGHAN.

IN the treatment of flexions of the uterus I have employed almost every known variety of pessary, both intrauterine and vaginal, and after a short trial I have found them either inconvenient or ineficient, and have had to discontinue using them. After masy experiments I succeeded in devising a pessary which in practice has proved to be very efficient in treating these uterine affections. The pessary is of easy application, and affords great comfort to the patient, relieving her of many of the distressing symptoms which often accompany displacements of the uterus, although from the short time that the pessary has been in use I am unable to state its value in effecting a cure. The following woodcut gives a very fair representation of the pessary.

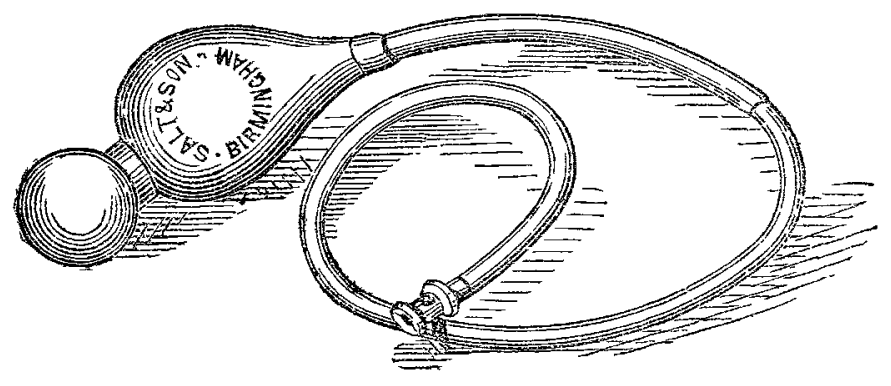

The pessary is made of india-rubber. It is, in fact, a small, almost inelastic ball, secured to an ordinary elastic pessary, and is so attached that its axis forms an obtuse angle with that of the larger part of the pessary. It is equally suitable for retroflexions and anteflexions. For an anteflexion of the uterus it is introduced in the following manner:-The instrument is dipped in tepid water, and its upper surface then smeared with a solution of gum arabic, to facilitate its introduction. I have used a solution of gum arabic for this purpose for some time, and find it to be a very good substitute for oleaginous and fatty matter's, which dissolve the india-rubber and destroy the integrity of the instrument. The pessary is now rolled up on its long axis, and passed under the pubes, along the anterior wall of the vagina, until the upper part is passed beyond the os uteri.
The pessary is then inflated, which forces the small portion of the pessary into its place-that is, between the uterus and bladder, restoring the uterus to its normal position. When the pessary is sufficiently filled with air the tube is made secure, and suspended to a band round the waist, or placed in some other convenient position. The pessary must be introduced with the small ball looking towards the uterus, for if it is passed in the opposite direction the upper extremity would press on the bladder, and the lower portion would exert undue pressure on the uterus. The inflation of the pessary may be effected either by the mouth or by means of Higgison's syringe, the two being connected by means of a small piece of india-rubber tubing.

For retroflexions of the uterus, it is only necessary to pass the pessary along the posterior wall of the vagina-reversing, in short, the introduction of the pessary to what obtains in cases of anteflexion.

The pessary was constructed, under my directions, by Messrs. Salt and Son, Bull-street, Birmingham.

Birmingham, Sept. 1869.

\section{A CASE IN WHICH A LIVE FISH FOUND ITS}

\section{WAY INTO THE CFSOPHAGUS, AND WAS} IMPACTED FOR ABOUT SIXTEEN

\section{HOURS.}

\section{B $\mathrm{Y} \quad$ T. STEWA R T, IN. D.,} SLRGEON 2XD EATt. 2IST FUSILIERS.

Two interesting cases of the impaction of foreign bodies in the csophagus have lately appeared in THE LANCET: one by Mr. Pollock-a case of impaction of artificial teeth; the other by Mr. Bond, where a patient, in a state of delirium, swallowed a metal buckle, with the leather attached. I am induced to record the following case, interesting from its rarity, inasmuch as the foreign body was alive when the accident happened, and probably remained so long afterwards, while imprisoned in the œsophagus.

On the morning of the 8th of May, 1869, a native puckally of the regiment, named Chenomully, was brought to the hospital of the 2nd batt. 21st Fusiliers, in a state of great distress--suffering from intense pain low down in the cesophagus. There was much difficulty in breathing, and the patient was unable to swallow liquids or solids. $\mathrm{He}$ assumed a posture leaning forwards, as the attempt to stand erect caused more distress. The patient stated, as also the friends who accompanied him, that on the previous evening, while fishing at "The Lake," he canght a fish, which proved unusually lively, and, in order to extract the hook from its gills, he seized the fish with the fingers of the left hand and the hook with his right, and, with the head of the fish between his teeth, effected his object. Ho had scarcely done so, however, when the animal, with its long, sharp, dorsal fin, pricked the palm of his hand, causing him suddenly to let go his hold, and involuntarily to open his mouth at the same time, when the fish bolted down his throat; and although he grasped it by the tail in its descent, and squeezed his pharynx with the other hand, all his efforts were ineffectual-the fish made its way to the position above described.

A live specimen of the kind of fish impacted had been brought to the hospital by the man's friends for inspection. It was about the same size, and caught the same evening. It appeared to be identical with the Anabas scandens (the walling perch of Cejlon), called by the Hindustanees here the sooma. This fish is remarkable for its power of locomotion on dry land (making lono marches by means of its pectoral fins), and for the length of time it can live out of water. It is said that the fishermen on the Ganges will keep these fish in earthenware vessels without water for four days, taking them out to cools when required, when they are as lively as when first taken. The speeimen under observation had been out of the water all night, and, on being touched or irritated, was able to walk with some rapidity. The fish was in length about four to five inches, an inch thick at the shoulder, and in depth about one inch and a half, including dorsal fin, as sharp as a knife standing up, fully one-half inch. The attempt to extract the animal 
with forceps, if such had been at hand, would have failed, and in all probability would bave caused serious injury, owing to the sharp dorsal fin, which, when erected to its full extent, inclines towards the tail of the animal ; the pectoral fins also inclining in the same direction. It was, therefore, decided to use the probang as the only alternative, and if possible push the animal into the stomach. Owing to the pain and spasm induced, a first attempt failed. On a second attempt the fish was dislodged, and I passed the probang fairly into the stomach, with but slight obstruction to the instrument. The patient shortly afterwards left the hospital, able to walk without the assistance of his friends, and relieved of all his distressing symptoms, and, beyond some pain on deglutition for some days afterwards, has since experienced no inconvenience.

Rangoon, June, 1869.

\section{ON A NEW METHOD OF USING NEEDLES IN THE OPERATION FOR HARELIP.}

\section{BX LAWSON TATT.}

I VENTURE to bring before the notice of practical surgeons an improvement in this operation, which I believe to be one of importance. It is an operation which is performed principally for wsthetic reasons, and it is frequently marred in this respect by the ungainly scars which are left by the needles when used in the ordinary way; in fact, I have not yet seen a case in which this defect has not been marked. What I propose is, that instead of two or more needles being introduced transversely through the flaps, they should be used in this manner: Having made what incisions he deems requisite for the operation (and I may here say that I have abandoned all the fancy manipulations for the old-fashioned straight incisions, removing plenty of tissue), the surgeon is to introduce two ordinary sempstress's needles, armed with a few inches of silver wire doubled, through the flaps, in the form of a St. Andrew's cross; the point of ,each needle is to be introduced through the mucous membrane of the lip, about half an inch from the edge of the flap, and brought out at the middle of the incision, then introduced into tho other flap at the point opposite, and brought out at the root of the ala of the nose. The needles cross in the middle of the wound. The flaps are to be carefully adjusted, then the heads of the needles to be pushed fairly into the lip, and pulled together by twisting the wires; the points of the needles are then to be cut off close to the skin, and the stumps retracted into the flaps. In this way nothing is left to "catch," and when the needles are removed, by untwisting the wires and pulling by them, there are no scars left.

In the last case in which I used this method the parents of the child, aged seven years, say that it is scarcely possible for a stranger to tell that the child had been operated upon, and in this case there was a complete and very wide intermaxillary cleft, which I had previously closed.

Wakefield, August, 1869 .

Charitable Bequests.-Mrs. Wiggins, widow of the late MIr. Robert Wiggins, a Liverpool merchant, has left the following legacies to medical charities in that town: -Royal Infirmary, \&1000; Dispensary, 21000 ; Northern Hospital, £1000; Southern Hospital, 21000 ; Ladies' Charity and Iying-in Hospital, $£ 500$; Infirmary for Children, 2500; Nurses' Institution, \$300; and the Eye and Ear Institution, \$300.-The late Rev. W. Bonaker, of Evesham, has by his will appointed the trustees of the Worcester Infirmary residuary legatees in respect of a valuable personalty and real estate, the income of which is to be invested at compound interest for sixteen years, and then applied towards the support, maintenance, and medical care of the patients in one of the wards of the Infirmary, to be thereafter styled the Bonaker ward.-The Royal Seabathing Infirmary, Margate, and the Sussex County Hospital, Brighton, get legacies of 21000 each under the will of the late Edward Giles, Esq., of Clapham.

\section{a dithror}

OF THE PRACTICE OF

\section{MEDICINE AND SURGERY} IN , THE

\section{HOSPITALS OF LONDON.}

Nulla autem est alia pro certo noscendi via, nisi quamplurimas et morborum tionum historias, tum aliorum, tum proprias collectas habere, et inter se comparare.--MoRGAGNI De Sed. et Caus. IIorb., lib. iv. Procmium.

\section{GUY'S HOSPITAL.}

[PATHOLOGICAL DEPARTMENT.]

CASE OF ACU'TE INFLAMMATION OF THE CEREBRAI ARTERIES DURING SYPHILIS.

(Autopsy by Dr. Moxon.)

THe following case is one of great significance, both as regards the clinical fact of syphilitic disease of the brain, and as regards the pathological question of the relation of syphilis to arterial disease. Syphilitic node or "gumma" of the brain is amongst the best attested diseases; but the evidence which should prove that syphilitic inflammations directly attack the cerebral arteries is as yet far from conclusive in its extent. Meanwhile the individual cases that have been published by Dr. Hughlings Jackson (Med. Times, 1866) and Dr. Moxon (Guy's Hospital Reports, 1867), although very few, are of a convincing character. The case which we are about to describe occurred in Guy's on July 31st, and is a very convincing example of acute syphilitic arteritis. The patient was a man, aged thirty-one, who was admitted July 29th, under the care of Dr. Fagge. He had suffered from syphilis, and had had headache for some months. He was seized at midday on the 29 th July with an apoplectiform attack. He was found to be unable to speak, and this neither from aphasia nor aphonia, but because he could not move his tongue. He had great difficulty in swallowing. His lips were weak, and the saliva dribbled from his mouth. His right limbs were almost completely paralysed; the left were weak. The heart's sounds were natural. He died about twenty-four hours after admission.

On examination of the body, Dr. Mozon found on the middle of the frontal bone a node, quite recent, in the form of a round patch of the size of a shilling and one-fifth of an inch in thickness; it was in the deep layer of the pericranium, resting on the bone; its deeper part was yellowish and opaque, and its superficial part minutely vascular; the bone itself was rather rough and porous-looking, and injected at the corresponding spot. This patch had all the characters of a syphilitic node on the bone. The surface of the cranium was uneven from older nodes. The dura mater was healthy. The arachnoid was rather thickened about the base of the brain and along the Sylvian fissure, but not at the vertex. Some of the cerebral arteries were diseased in a very remarkable manner. The basilar artery especially had its size increased greatly, and its colour was of a milky white, so that for a length of three quarters of an inch it looked like a piece of boiled maccaroni; but its colour was at points more opaque, and its surface rather more irregular. The right vertebral artery was very small; the left was proportionately large, and it was thickish and rather opaque and stiff. The change in the basilar artery was rather abrupt at both ends of the affected patch. On opening up the basilar artery, the channel was found to be continuous through it, but narrowed to half its natural size from the swelling of its walls. These were soft and fleshy, having all the qualities of firm lymph. The microscope showed that the lymph-like appearance was not deceptive, for the swollen wall of the vessel was composed of closely aggregated corpuscles having all the characters of inflammatory corpuscles; these were in layers between swollen remains of the proper coats of the vessel. Thus there was no doubt whatever of an acutely inflamed state of the arterial wall, and the correspondence of the lymph on the arterial wall with that in the pericranial node was marked 